temperature at once; in exceptional cases colder water or longer immersion may be needed; $103^{\circ}$ to $105^{\circ} \mathrm{F}$. in the axilla is easily lowered to $96^{\circ}-99^{\circ} \mathrm{F}$., equivalent after a bath to a rectal temperature of $99^{\circ}-101^{\circ} \mathrm{F}$. In proportion, the axillary temperature falls less than the rectal immediately after the bath, and rises more after an interval. 2. It slows the pulse on an average by twenty beats a minute (except in cases in which it is but little quickened), steadies it, and diminishes dicrotism, and thus improves its tone. 3. It tends to moisten the tongue, improves the aspect of the patient, promotes the taking of nourishment, and courts refreshing sleep. 4. It restores consciousness and dissipates delirium, particularly when noisy, and especially if used with opium and brandv; and thus it saves nurses wearing labour and patients the discomfort, or worse, of physical restraint. 5. It causes forced inspiration, and, by expanding the lungs, lessens the tendency to bypostatic pneumonia. 6. It has seemed to prevent excessive diarrhoea, and to render abortive cases bathed from the beginning. On the other hand, it increases relapse, and patients rarely like it, but generally simply detest it

I am, Sir, your obedient servant

Iadbroke-grove, W., August 21st, $1883 . \quad$ W. TONGE-SMrTH.

\section{"LENGTH OF INCISIONS IN OVARIOTOMY."} To the Editor of THE LANCET.

SrR,-If Mr. Owens had cared to pursue his observations further I could have shown him three cases I operated upon last week, where the lengths of the incisions were as follows : 1. Fibroid tumour, removal of ovaries and tubes, troublesome bleeding from adhesion of one tube to side of pelvis; incision enlarged to two inches and a half. 2. Parovarian cyst ruptured and adherent; length of incision two inches. 3. Removal of both ovaries and tubes, degenerated and adherent; length of iucision one inch, five lines. All of these have done well, and have not given any anxiety. have long recoynised the value of short incisions: but I could show him some cases where the incisions have not been short or the results gratifying. I could not point out any case where the solid part of a tumour has been removed through an opening of smaller diameter than that represented by the narrowest diameter of the growth itself. Two circumstances should be noted to obtain a correct impression of his remarks: whether the incision is measured upon $a$ distended abdomen at the time of operation, or when this is completed and the parts brought together by stitches ; and what is meant by "ovariotomy," some including under this term the removal of ovaries of normal or slightly increased size. In the majority of cases of abdominal section it is sufficient to get two fingers into the abdomen, and it is hardly possible to manipulate well with. out; the transverse measurement of these may represent the length of the incision. In some cases of thin cysts I have pat not more than one finger into the cavity to explore, but If am satisfied that where there are adhesions or bleeding, these cannot be properly dealt with in any other way than by inspection The condition of the parts-thickness or thinness of the wall, depth of pelvis, and position of omentum and intestine-these regalate the incision necessary.

I cannot tell how Mr. Owens interprets Listerism, but I am assured that the perfection of modern surgery is largely indebted to Mr. Lister's forc: ble advocacy of absolute cleanli ness and attention to details. It is usual, I have found, for the temperature to be sightly raised when the spray or carbolic acid solutions are $\mathrm{u}=\mathrm{ed}$, but then this can be estimated accordingly; where cases mean to do well it is very soon indicated, and geverally there is very little elevation of temperdture after thirty-six hours. Mr. Sydney Jones no doubt is very well able to defend his own practice, hut the cases quoted point to one great fact, that in a general hospital real and substantial success may be attained.

I am, Sir, yours truly,

Birmingham, Aug. 18th, 1883 EDWARd Malins.

\section{To the Editor of THE LANCET.}

SIR,-It is hardly possible that Mr. Owens can have earefully read the cases done by Mr. Sydney Jones which he quotes, for he cites without details cases done by another surgeon, and quite overlooks the reason for the incision in the case of $\mathrm{E}$. J-, which was about six inches - viz., that the wall of the cyst was intimately adherent to the peritoneum; ard, besidis there were other adhesions which were somewhat numerous and firm. The operation was difficult, even with a long incision, and the increased length of the wound was a safeguard against that bruising of the edges of the wound which must other wise have resulted from the necessary manipulation. Again, it is difficult to see how any large amount of solid matter could be got through an incision an inch and a half long. Does practical experience of cises after ovariotomy prove that long firm cicatrices cause any inconvenience to patients after the operation? I thiuk not. Is it rare to find a certain amount of traumatic temperature after an operation of the masnitude of those under discusxion? I think that it is the practice of some ova:iotomists to operate only on cases likely to improve their average; perhaps those mentioned by $\mathrm{Mr}$. Owens were cases of the kind. The increased length of incision certainly facilitates operation, and the healing proces is not thereby delayed; the wound being practically healed at the end of a week, when the first dressing is done. I have seen Mr. Sydney Jones perform ovariotomy in a very large number of cases, and it is his practice to regulate his ircision in accordance with the kind of tumour and the history of the case, preferring of course an incision compatible with ease of performance of operation and safety uf patient. Spray of the strength of 1 in 80 carbolic acid is used, and antiseptic dressings are rigidly adhered to.

I am, Sir, yours obediently, WILLIAM H. BATTLE, Surgical Registrar.

St. Thomas's Hospital, August, 1883.

\section{ABDOMINAL TUMOURS.}

\section{To the Editor of THE LANCET.}

SrR,-I have read with interest the report of a case of an "Enormous Myxo-lipomatous Tumour within the A tudomen," reported by Joseph Wigglesworth, M.D., in your journal of June 30th. In connexion with the account of this interesting case, I beg to call attention to a specimen of colossal abdominal tumour which $I$ presented to the $P$ athological Society of this city, under the date of February $27 \mathrm{lh}, 1873$, a record of which appears in volume iv. of the Transactions of the Society. During life the late Dr. Washington L. Atlee was asked to see a patient, a woman aged abut fifty years, in consultation, with a view to the performance of ovariotomy. Although the symptoms presented were clearly those of cystic ovarian disease, the precaution of tapping was taken, and the result wassuch as to decide against any operative interference. The history was that of an abduminal growth which had, in a comparatively short per od of time, attained enormous proportions. The circumstanc-s under wbich the autopsy was made were such as to preclude any very accurate dissection. It was quite manifest that the growth originated and was developed within the peritoneal cavity. No pedicle could be discovered. Extensive adhesions existed between the parietes and viscera of the abdomen. The weight of the tumour was estimated to be between forty and fifty pounds. I transcribe the report of the commistee on morbid growths, to which the speicimen was referred. "Your committee, having examined the colossal abdominal tumour presented by Dr. Mears, beg leave to report that they consider it to be a mvxo-sarcoma. Different histological elements were found to exist in different portions of the growth. The prevailing structure, however, is the sarcomatous, with its large round nucle $t$ ed cells; these are embedded in a delicate network of fibrillates interstitial substance. A few giant cells, containing eight to ten nuclei, were also observed. At other points, where the growth assumed a softer, semi-transparent. jelly-like consistence, the prevailing structure is myxomatous, with its stellate anastomosing cells embedded in a hyaline suhstance that is rendered cloudy upon the additinn of acetic acid." From the microscopic appearances alnoe, the committes was unable to determine the origin of the growth. "Klebs, who has examined a number of immense and rapidly growing abdominal tumours closely in every re=pect resernhling this specimen, states that they are, as a ruls, either lyophosarcomata of the mesenteric glinds, or myxomatous deg-nerations of lipomata of the omentum." Feeling that this case possessed some features of interest, which it might be 
prolitable to study in connexion with tbat so fully reported by Dr. Wigglesworth, I have taken the liberty of calling attention to it in your columns.

I am, Sir, your obedient servant,

Philadelphia, July 23rd, 1833. J. EWING MEARS, M.D.

\section{To the Editor of THE LANCET.}

SIR, - In The LANCET of July 7 th is the report of a case of abdominal tumour with an unusual course and termina. tion, treated in the Leeds General Infirmary, under the care of Dr. Clifford Allbutt. About eight years ago I had a case here under treatment so nearly resembling Dr. Clifford Allbutt's in its general features, and also in its particular details, that it must have been the same disease. No notes of the case were taken, but its obscurity and apparent strangeness impressed me so vividly at the time that a distinct recollection of its main features has remained with me ever since. The case was very shortly as follows : A. $\mathrm{H}-$, aged about twenty, began to complain in December, 1875 , of very severe pain in the abdomen of some what intermittent character, growing always worse at night, and be coming so intense as the night advanced that he rolled about in the bed in agony, sometimes finding most relief on his elbows and knees. On these occasions, as the pain reached this degree, I night after night gave a hypodermic injection of morphia, which almost invariably subdued the pain, and allowed him to get a few hours' sleep. Vomiting was occasional onlv, not so distressing and prominent a symptom as in Dr. Clifford Allbutt's case. This state of matters went on for about six weeks; the wearing pain, with intense paroxyems, the want of sleep, the inability, from derangement of the digestive organs, and sometimes pretty frequent vomiting, to obtain more than a very small amount of nutriment, reduced the patient to a state of great weakness and emaciation. About this time an abdominal tumour was noticed, which rapidly increased in size. It was situated between the umbllicus and epigastrium, and soon attained the size of a foetal head, having a globular form and a feeling of elasticity and distension. When the tumour began to assume this size the pain somewhat abated. Along with a medical friend I aspirated the tumour, and the glass was immediately filled with a reddish-brown liquid; but further proceedings were prevented by an accident to the aspirator. Another operation was rendered unnecessary for two or three days after this. Diarrhoea came on of a greenish black viscid matter, exactly resembling, excepting that its viscidity was greater, that drawn off by the aspirator. The chamber utensil was filled more than once with this matter; the tumour completely and almost simultaneously disappeared, the pain likewise; and an uninterrupted progress towards recovery took place. He soon afterwards was able to go to the seaside, and returned in perfect health.

The after-history is the most encouraging part of the case. Eight years have passed, and A. HC is living in this town in perfect health. About four years since he had a slight attack of the same kind of pain, which yielded to the injection of morphia as before, and only troubled him for two or three days. No appearance of tumour or other consequence followed, and since then he has never suffered from any symptoms of the kind.

I am, Sir, yours truly,

J AMES MENZIES, M.D., L.R.C.S.Ed.

Galashiels, N.B., July 19th, 1883.

\section{SURGEON-DENTISTS AND DENTAL SURGEONS.}

To the Editor of THE LANCET.

Sre,-I trust you will permit me, through the medium of THE LANCET, to call attention to a growing evil. It is one of such a nature that if not nipped in the bud, it will act disastrously in the future towards the interests of the younger members of our profession. I allude to the practice amongst so-called "surgeon-dentists" of acting in all respects as if they were registered medical practitioners. To quote one instance of many which have come under my notice. A patient of mine, Miss __, consulted a dentist for toothache. IIe informed her that her toothache was attributable to derangement of the liver, and that he would come and see her at her home. Her father objected to this procedure, which, however, did not debar him from sending two bottles of medicine. This is not an isolated case, and I am disposed to think that it is not an idiosyncrasy of London dentists. I am aware that such acts of prescribing are an infringement of the Apothecaries Act; but who is to prosecute? General practitioners cannot unless they desire to expose themselves to obloquy and ridicule. In these days of counter-prescribing chemists, provident dispensaries, grossly abused out-patient departments of hospitals, and an ever-encroaching army of consultants, if to all these we add prescribing dentists, the day is not far distant when the general practitioner will be squeezed out and obliterated.

I am, Sir, yours faithfully,

Clapton, July 29th, 1883.

F. W. EAst, M.B.

\section{To the Editor of THE LANCET.}

SIR, -Now that there is an all but sure prospect of the passing of the Medical Act Amendment Bill, is it not a stern necessity that once for all a stop should be put to the improper use of the word "surgeon" in conjunction with that of dentist, to be seen at every street corner, as used by men keeping druggists' shops, \&c. ? There may, perhaps, be some excuse for those men using it who, to obtain a dental licence, have undertaken a full curriculum of study; but as a member of my college I do most emphatically protest against the assumption of this title by the hundreds of men who claim (on the mere grounds of having gone to Dublin or elsewhere, and by the payment of $f 1010 \mathrm{~s}$. and the passing of a modified examination "sine curriculo") the right to place surgeon-dentist or dental surgeon upon their doorplates, window blinds, \&c. But even supposing these to have some honorary or legal claim to this hard-earned title, the thousands of other men who have not done even this can have no possible right to prostitute this qualification by making use of it in any shape or way. The leaders of dentistry, whilst professing to do all they can to place this, their profession, on a solid and honourable footing, ought now to take this opportunity of separating the chaff from the wheat; whilst, once for all, we as a fraternity have now the chance of protecting ourselves from the improper assumption of our rights and titles by men who can have as little right to their use as knowledge of the duties and obligations such titles demand at our hands. If as a profession we have reason to be proud that the Queen has seen fit to bestow the honour of knighthond on an eminent Fellow of the College, who whilst making dentistry his specialty ranks high in other branches of his profession, we cannot but deplore the fact that "erstwhile" mechanics, policemen, factory operatives, and hairdressers use the title of surgeon, whilst to my personal knowledge many chemists claim to use it whose only title to do so is that. on the strength of their extracting teeth at $3 d$. each, on the passing of the Dental Act in 1878 they, by payment of $£ 22 s$, obtained registration as dentists, and along with it the purchase of a before undreamed of dignity.

August, 1883.

I am, Sir, yours \&c.

\section{THE VALUE OF ETHER IN COLLAPSE To the Editor of THE LANCET.}

SIR,-Having read in your last issue the report of a case in which ether, subcutaneously injected, proved of the utmost value, I $\mathrm{k}$ hould like to record a case which occurred in the obstetric practice of this hospital. A few weeks ago I was sent for to a case of very severe post-partum hremorrhage. The house was luckily situatea almost opposite the hospital. I found the patient in a most critical condition; she was insensible and pulseless. The friends stated that before unconsciousness supervened she had been violently convulsed. Her face was of a ghastly hue and covered with a clammy sweat; the extremities were cold; in fact, I beliered at first that she was dead. But over the heart could be felt a feeble flutter. The condition of the patient made it evident that if any restorative could be of any service it must be given at once. I therefore injected subcutaneously a syringeful of ether (thirty minims), which I had fortunately ordered to be sent across when I left the hospital. It acted like a charm, for in two or three minutes the heart rallied suffi. ciently to receive benefit from an enema of brandy and strong 